\title{
Tomás Ariztía (ed.) (2012), Produciendo lo Social. Usos de las ciencias sociales en el Chile reciente (Santiago: Ediciones UDP). $350 \mathrm{pp}$.
}

\author{
ANTOINE MAILLET \\ Pontificia Universidad Católica de Chile \\ Institut d'Etudes Politiques de Paris
}

Produciendo lo social es un libro editado por Tomas Ariztía, que reúne las contribuciones de sociólogos, politólogos, historiadores y filósofos en torno a un objetivo ambicioso: estudiar los usos de las ciencias sociales y el efecto de ellas sobre el mundo social en el Chile contemporáneo. En los términos de Ariztía, se trata de "examinar no tanto la capacidad de estas disciplinas para estudiar y reflexionar sobre lo social, sino para producirlo y afectarlo" (p. 10). El libro se inserta en la literatura reciente sobre las relaciones entre el mundo académico y la política, a la vez que trasciende este objeto. Brillante y estimulante reformulación de la agenda sobre la experticia y los expertos, constituye un libro de gran interés no sólo para los investigadores interesados en esta temática, sino también para todos los politólogos preocupados por el impacto de los hallazgos de la disciplina fuera de ella.

El libro consta de tres partes. La primera lo sitúa en las discusiones que alimentaron en los últimos años títulos como En nombre de la razón (Silva, 2010) y Notables, tecnócratas y mandarines (Güell y Joignant, 2011). Se trata de un abordaje clásico de las relaciones entre las disciplinas académicas y la acción pública, prestando atención a la forma en que individuos con altas calificaciones académicas participan en política. En su contribución, Montecinos y Markoff proponen una mirada a nivel del continente sobre la participación de los economistas en la política. Luego, la reedición en castellano del clásico texto de Silva sobre el reemplazo de los Chicago Boys por "los monjes de Cieplan", concomitante con la transición democrática el año 1990, afianza el anclaje del libro en la tradición "nacional" del estudio de los expertos. Esta primera parte se concluye con un estudio de Gárate sobre CIEPLAN, que prolonga el trabajo de Silva en una mirada más centrada sobre el think tank como institución que sobre las trayectorias individuales.

Las dos otras partes del libro amplían el objeto y el abordaje conceptual respecto de la agenda tradicional sobre experticia y política. El concepto clave, que unifica las contribuciones, es el de performatividad, decisivo para pensar las operaciones de construcción de lo social de las cuales participan las ciencias sociales. El foco está en la "capacidad de las ciencias sociales para producir nuevas realidades como resultado de su propia operación de descripción" (p. 14). Ramos, en su contribución, vuelve sobre los orígenes de este concepto en la obra del filósofo inglés John Austin, quien indicó que "afirmar es desempeñar un acto" (p. 223). En este sentido, las ciencias sociales realizan "actos de habla", que tienen efectos en lo social. En palabras de Ariztía, estos capítulos se inscriben en una visión del "mundo social no como entidades fijas y estables esperando ser descubiertas por la ciencia, sino como el resultado de un proceso activo de ensamblaje y producción, en la cual las ciencias sociales juegan un rol central" (p. 11). 
En consecuencia, las contribuciones de las partes II y III del libro no están focalizadas en los individuos y sus trayectorias, sino en los productos de las ciencias sociales, y en cómo circulan más allá de las fronteras formales del mundo académico. Los autores constituyen en objeto de estudio distintas manifestaciones de los resultados de las ciencias sociales. Frente a la imposibilidad de abordar detalladamente todas las contribuciones, esta reseña se focaliza en tres capítulos que tienen una relación directa con la ciencia política.

Ariztía y Bernasconi analizan el efecto en términos de producción de lo social de cuatro libros que identifican con una corriente de "sociología chilena con vocación pública" de los años 90 -cuyos autores son Brunner, Garretón, Moulian y Tironi-. Estos libros comparten el propósito inicial de describir las transformaciones ocurridas en la sociedad chilena durante la dictadura, y sus consecuencias en la década siguiente. Esta interrogación común respecto a una interpretación del presente se articula en torno al concepto de modernidad. Apreciaciones distintas del concepto llevan a diagnósticos diferentes, según se considere la modernidad como una experiencia vinculada a la modernización, en particular económica (Brunner, Tironi) o un proyecto de emancipación (Moulian, Garretón). Estas diferencias teóricas tienen fuertes implicancias normativas, donde Brunner y Tironi plantean mejorar la gestión de esta modernidad, Garretón y Moulian apuntan a establecer las bases para una acción transformadora. Los caminos distintos que toman los autores, a partir de un mismo proyecto inicial, ilustran de qué forma el acto de habla de constatar produce una acción performativa, con efectos sobre la realidad social. Una encarnación fuera de las ciencias sociales de estas distintas visiones es la famosa controversia entre autoflagelantes y autocomplacientes, que podría ser una traducción de estas dos visiones de la modernidad.

En otro capítulo, Ramos trabaja en torno a la "performatividad" de los "Informes de Desarrollo Humano" publicados por el PNUD entre 1996 y 2004. En particular, establece la manera en que el efecto de realidad producido por estos textos se fundamenta en un complejo "agenciamiento socio-técnico". Este dispositivo tiene como componente fundamental los textos mismos, producidos según metodologías que le otorgan una legitimidad científica, pero también incluye otros elementos. Por un lado, aparecen mecanismos clásicos de difusión, como las redes en las cuales se inserta la institución emisora, o la campaña mediática que acompaña los informes. Por el otro, incorpora una reflexión sobre las características mismas del objeto "informe", como la emergencia de un código visual que pone el énfasis en las fotos y los gráficos, elementos que permiten una mejor transmisión hacia espacios no científicos. La combinación de estas múltiples características permite tener una amplia presencia en el campo académico, la esfera pública y la institucionalidad estatal. En estos distintos ámbitos los textos producen un efecto performativo, en la medida en que las "diversas construcciones realizadas por este organismo -las cuales articulan elementos teóricos, conceptuales, metodológicos y retóricos-han sido aceptadas y asumidas como expresiones de la realidad social" (p. 248).

Otro objeto de estudio de la performatividad de las ciencias sociales en el ámbito político son los 113 "informes de análisis" redactados para el presidente Aylwin bajo la dirección de Edgardo Boeninger entre 1990 y 1994. Complementando su trabajo sobre los "technopols" (Güell y Joignant, 2011), Joignant analiza el contenido de estas minutas que circularon dentro de un grupo restringido de ministros y asesores del primer gobierno post-dictadura. Vincula los análisis y recomendaciones presentados en estos documentos con la literatura sobre las transiciones políticas, e infiere cómo los marcos 
analíticos desarrollados en ellas son movilizados por los autores para categorizar actores y situaciones de la transición chilena, produciendo así efectos performativos. Pone de relieve cómo un trabajo esencialmente teórico como lo son los análisis de Linz, Schmitter o Przeworski pueden ser transformados en una "caja de herramientas" (p. 332) para la acción política. Estas operaciones pueden llegar a ser lo que Joignant llama "golpes de fuerza teóricos" (p. 333) en el caso de la reinterpretación para el caso chileno de la teoría de la "democracia consociativa" de Lijphart, donde se evidencia una larga distancia entre el concepto original y su versión criolla.

Como se aprecia en estos tres ejemplos, el contenido del libro es muy diverso. La amplitud del objeto es sin duda una ventaja del libro, que logra el objetivo propuesto de observar los efectos de las ciencias sociales en distintos ámbitos. Salta hábilmente las barreras disciplinarias para instalar una reflexión teórica transversal potente. Sin embargo, la vastedad del objeto constituye también un flanco, en la medida en que ineludiblemente algunas preguntas quedarán sin respuesta.

Formulo dos críticas al libro. Ambas nacen de una misma problemática, en torno al perímetro de las ciencias sociales en cuanto objeto de estudio. El carácter impensado de este perímetro en el libro genera dos tipos de problemas. Por cierto, estos puntos ciegos se deben también al carácter innovador de la reflexión propuesta, y es posible verlos como oportunidades para desarrollar más adelante la agenda formulada aquí. En primer lugar, el carácter general de la interrogación por los efectos de las ciencias sociales hace que el libro no trate la pregunta del alcance y los límites de estos efectos. En segundo lugar, al unir todas las disciplinas de las ciencias sociales bajo esta misma etiqueta, los autores no se dan la posibilidad de diferenciar entre los efectos sociales propios a cada disciplina, en particular para diferenciar efectos generalizados de asuntos más puntuales.

Así, el primer problema con la ausencia de límites al objeto es que llega a ser perjudicial para el mismo proyecto de pensar los usos de dispositivos oriundos de las ciencias sociales, pero que al alejarse de su lugar de origen podrían haber perdido este vínculo. Los autores no parecen considerar los casos potenciales de versiones empobrecidas o instrumentalizadas de productos de las ciencias sociales. Un caso de la posible desaparición de este vínculo inicial podrían ser las encuestas de opinión. Dentro de la diversidad de estos objetos, algunas forman parte de un circuito exclusivamente comercial, y son producidas sin una reflexión científica, sino únicamente con un propósito práctico. En estas condiciones, su relación con el ámbito de las ciencias sociales se hace muy tenue, hasta probablemente inexistente.

Tratar este problema permitiría acotar el objeto de estudio para futuras investigaciones. Sin reflexión sobre los límites del perímetro de las ciencias sociales, y los efectos propios a la difusión hacia otros espacios, el terreno social aparece como un espacio continuo y homogéneo, lo cual no es. En este sentido, la reflexión desarrollada en este libro parece llevar también hacia la pregunta inversa por los espacios donde no se usan las ciencias sociales. ¿Cuáles son los límites para su difusión? ¿Por qué ideas y prácticas bien arraigadas en las disciplinas no se transmiten hacia la esfera pública o la acción pública? La pregunta no es trivial, pero el libro la evacúa completamente, dando a veces la visión de un mundo donde las ciencias sociales serían omnipresentes -y casi hegemónicas-. Al revés, me parece que se podría estudiar también la medida en que las ciencias sociales son sujetas a lógicas propias de otros campos -por no decir dominadas-, por ejemplo, por lógicas comerciales o de poder. 
La segunda crítica apunta al mismo problema de imprecisión sobre el lugar real de las distintas ciencias sociales en Chile. En ningún momento se considera una posible desigualdad entre las ciencias sociales en cuanto a su capacidad respectiva de producción de lo social. El libro muestra en este sentido cierta ambigüedad respecto de la economía. Aparentemente considerada como una ciencia social como las otras, no deja de recibir un tratamiento específico, evidenciado por la ausencia de algún economista en la nómina de autores. Por lo tanto, se trata más bien de la mirada de los representantes de algunas disciplinas sobre otras, sin que haya reciprocidad. No discuto en su esencia la naturaleza social de la economía, sino más bien de la economía practicada y enseñada en el Chile contemporáneo, donde predominan visiones a-históricas, generalmente neoclásicas, desde hace varias décadas. En esta situación, la pregunta es entonces el valor heurístico de discutir del efecto de las ciencias sociales en general, incorporando a la economía bajo esta etiqueta. Analítica y estratégicamente, pensando en el posicionamiento de las ciencias sociales en el espacio público, parece más apropiado tratar la economía aparte. Incluso, es lo que en la práctica el libro hace, pero no explicita. Podría asumir que la economía en cuanto disciplina, o discurso público, tiene una capacidad mayor a otras ciencias sociales para moldear lo social. $\mathrm{O}$ al menos podría diferenciar precisamente los espacios donde cada ciencia social -y los abordajes multidisciplinarios-produce efecto.

Estas críticas no vienen a opacar el gran interés del libro para quien se preocupa por la difusión del conocimiento académico de nuestras disciplinas hacia otros ámbitos, sea por una preocupación científica, sea incluso por el afán de propiciar una mayor influencia. En la primera dimensión, viene a aportar a una dimensión reflexiva sobre el desarrollo nacional de las ciencias sociales, propiciando debates que no se han dado suficientemente. En particular para la ciencia política, disciplina que llega hoy en día a producir más de 400 egresados anuales, la pregunta sobre la relación entre la producción académica, la formación que se entrega y el ejercicio profesional es muy relevante. La performatividad, y en general la reflexión sobre la producción de lo social, son temas que merecen la atención de los politólogos. Este libro establece fundamentos teóricos y empíricos sólidos para esta discusión y merece ser ampliamente reconocido por lo mismo para que a su vez contribuya a la producción de lo social.

\section{BIBLIOGRAFÍA}

Güell, Pedro y Alfredo Joignant. 2011. Notables, tecnócratas y mandarines. Santiago: Ediciones UDP. Silva, Patricio. 2010. En el nombre de la razón. Santiago: Ediciones UDP.

Antoine Maillet. Candidato a doctor en Ciencia Política, Pontificia Universidad Católica de ChileInstitut d'Etudes Politiques de Paris.

E-mail: avmaille@uc.cl 